\title{
The prevalence of multiple sclerosis in South East Wales
}

\author{
R J SWINGLER, D A S COMPSTON \\ From the Section of Neurology, University of Wales College of Medicine, Cardiff, UK
}

SUMMARY A population-based survey of multiple sclerosis in the county of South Glamorgan has demonstrated a prevalence of $441 / 376718\left(117 / 10^{5}\right)$. Eighty six per cent of the patients $\left(101 / 10^{5}\right)$ had definite or probable disease and $14 \%\left(16 / 10^{5}\right)$ had suspected multiple sclerosis on $1 \mathrm{January} 1985$. The estimated average incidence is $5 \cdot 41 / 10^{5}$ /year for the period $1947-84$ and it has risen significantly over four decades. The prevalence is similar to that found in a recent survey from the south east of England but significantly lower than revised figures from Scotland.

The first population-based study of multiple sclerosis was performed in north Wales in $1929^{1}$ and the results of over 200 surveys have since revealed an unusual world distribution with increasing frequency at greater latitudes. ${ }^{23}$ There is a north-south gradient in the United Kingdom ${ }^{4}$ and whilst this may be related to variations in ascertainment ${ }^{5}$ it has been suggested that genetic factors may also be partly responsible. ${ }^{46-11}$ To test this hypothesis it is necessary to perform combined epidemiological and immunogenetic studies in which the age and sex-specific prevalence of multiple sclerosis is accurately ascertained in an area where the frequency of HLA antigens in patients and healthy controls is also known.

\section{Patients and methods}

\section{Area}

The county of South Glamorgan in south east Wales covers 41,630 hectares and lies at a latitude of $51^{\circ} 30^{\prime}$ north and a longitude of $3^{\circ} 15^{\prime}$ west $^{12}$. The estimate of those usually resident on census night 1981 was 376,718 , of whom 269,459 $(71.5 \%)$ were living in the urban area of Cardiff and 107,259 $(28.5 \%)$ in the rural Vale of Glamorgan. Immigration from other parts of the United Kingdom and elsewhere caused the population to grow during the industrial revolution but it had declined by $1.6 \%$ in the decade preceeding the 1981 census.

According to 1981 census estimates 299,681 residents (79.6\%) were born in Wales, 58,974 (15.6\%) came from other parts of the United Kingdom and 18,063 (4.8\%) were born elsewhere. ${ }^{12}$ Of a $10 \%$ random sample of the census popula-

Address for reprint requests: D A S Compston, Section of Neurology, University of Wales College of Medicine, Heath Park, Cardiff CF4 4XW, UK

Received 21 June 1988.

Accepted 21 July 1988 elsewhere. ${ }^{12}$ Of a $10 \%$ random sample of the census population 8,666 (23\%) were in social classes 1 and 2, and 54,869 $(14.6 \%)$ were aged 65 years or older. Blood group data suggest that the indigenous inhabitants of rural north and south Wales are genetically distinct ${ }^{13}$ but there is also historical evidence for extensive migration to the industrial south from other parts of the United Kingdom. ${ }^{14}$

The area is served by 214 general practitioners and 45 hospital physicians, including three neurologists. The Welsh Office collects information on all individuals discharged from state hospitals in the Principality as part of the hospital activity analysis performed throughout England and Wales. These returns indicate that less than $1 \%$ of residents hospitalised with a neurological problem attend units outside South Glamorgan. ${ }^{15}$

\section{Method}

Five sources were used to produce a provisional nominal list of identified cases of multiple sclerosis. First, all patients discharged with a diagnosis of multiple sclerosis were identified from the department of neurology in-patient diagnostic index available from 1946. Secondly, information about patients discharged from other hospitals in the county was obtained from a second diagnostic card index kept by the principal hospital in the area between 1946-66 and from the computerised hospital activity analysis returns for the period 1967-85. Thirdly, all general practitioners in the area were asked to identify patients with multiple sclerosis known to them and permission for interview was sought. Fourthly, the membership list of the local branch of the Multiple Sclerosis Society was examined. Lastly, community nurses and physiotherapists were asked to provide information on patients under their care. The local social services disability register was not examined because it contained little diagnostic information.

The above sources were used in conjunction with hospital records to produce a provisional register. This was then sent to the local Family Practitioner Committee and the National Health Service Central Register for tracing; ${ }^{16}$ the returns were 
used to obtain a provisional but unreviewed estimate of prevalence. ${ }^{14} \mathrm{Up}$ to three attempts were then made to contact and subsequently interview each patient recorded on the provisional register. Using this information, personal interviews and existing records all living and resident patients were classified using the Poser criteria ${ }^{17}$ to give a reviewed estimate of prevalence for 1 January 1985. Patients who would have been previously diagnosed as having "possible" multiple sclerosis ${ }^{18}$ but who did not meet these revised criteria for "definite" or "probable" disease were assigned to a category of "suspected" multiple sclerosis. Age and sex specific prevalence rates were calculated using these criteria ${ }^{17}$ and the age and year of onset was tabulated for prevalent patients. By assuming that the average patient was seen at a random time during the course of the illness it was possible to estimate the duration from onset to death by doubling the time between onset and prevalence day. ${ }^{19}$ The year of diagnosis was recorded for both living and dead patients and these data were used to calculate estimated incidence rates from 1947 to 1984 . Trends in incidence were examined using Spearmans coefficient of rank correlation. In order to make the present findings comparable with previous surveys from the United Kingdom the patients were reclassified using the criteria previously proposed by Allison and Millar, ${ }^{18}$ and the method of Williams and McKeron ${ }^{5}$ was used to calculate a standardised prevalence ratio using the 1961 survey of Northern Ireland as a standard. ${ }^{20}$ Confidence intervals for estimates of prevalence were obtained from tables of the Poisson distribution. ${ }^{21}$

\section{Results}

Table 1 gives the number of patients on the provisional and prevalent registers identified by each method of ascertainment and the proportion that would have
Table 1 Ascertainment of multiple sclerosis in South Glamorgan

\begin{tabular}{lcccc}
\hline Source & $\begin{array}{l}\text { Provisional } \\
\text { Register }\end{array}$ & $\begin{array}{l}\text { Prevalent } \\
\text { Register }\end{array}$ & $\begin{array}{l}\text { Sole source } \\
\text { of } \\
\text { identification }\end{array}$ \\
\hline Departmental index & $795(89 \%)$ & $420(95 \%)$ & $33(7.5 \%)$ \\
Hospital activity & $610(68 \%)$ & $271(61 \%)$ & $3(0.7 \%)$ \\
General practice & $381(43 \%)$ & $340(77 \%)$ & $4(0.9 \%)$ \\
$\begin{array}{l}\text { Multiple Sclerosis } \\
\text { Society }\end{array}$ & $90(10 \%)$ & $85(19 \%)$ & $1(0.2 \%)$ \\
Community nurse & $16(1.8 \%)$ & $16(3.6 \%)$ & $0(0 \%)$ \\
Total & $894(100 \%)$ & $441(100 \%)$ & - \\
\hline
\end{tabular}

been missed if that source had not been available. Of the provisional cases $795 / 894(89 \%)$ were identified from the departmental diagnostic index, 610/894 $(68 \%)$ from the computerised search of hospital activity records. $148 / 214(69 \%)$ of general practitioners responded to the circular and identified 381/894 $(43 \%)$ cases. The South Glamorgan branches of the Multiple Sclerosis Society listed $90 / 894(10 \cdot 1 \%)$ as members, and a further $16 / 894(1.8 \%)$ were known to community nurses and physiotherapists. Of the prevalent patients $420 / 441(95 \%)$ were identified from the departmental index, 271/441 (61\%) using hospital activity analysis returns, $340 / 441(77 \%)$ by general practitioners, 85/441 (19\%) from the membership lists of the Multiple Sclerosis Society and 16/441 (3.6\%) by appeals to local district nurses and physiotherapists. In all $33 / 441(7.5 \%)$ of patients were only identified from departmental records, $3 / 441(0.7 \%)$ from the returns of the hospital activity analysis, $4 / 441(0.9 \%)$ from general practice records, $1 / 441(0 \cdot 2 \%)$ by the

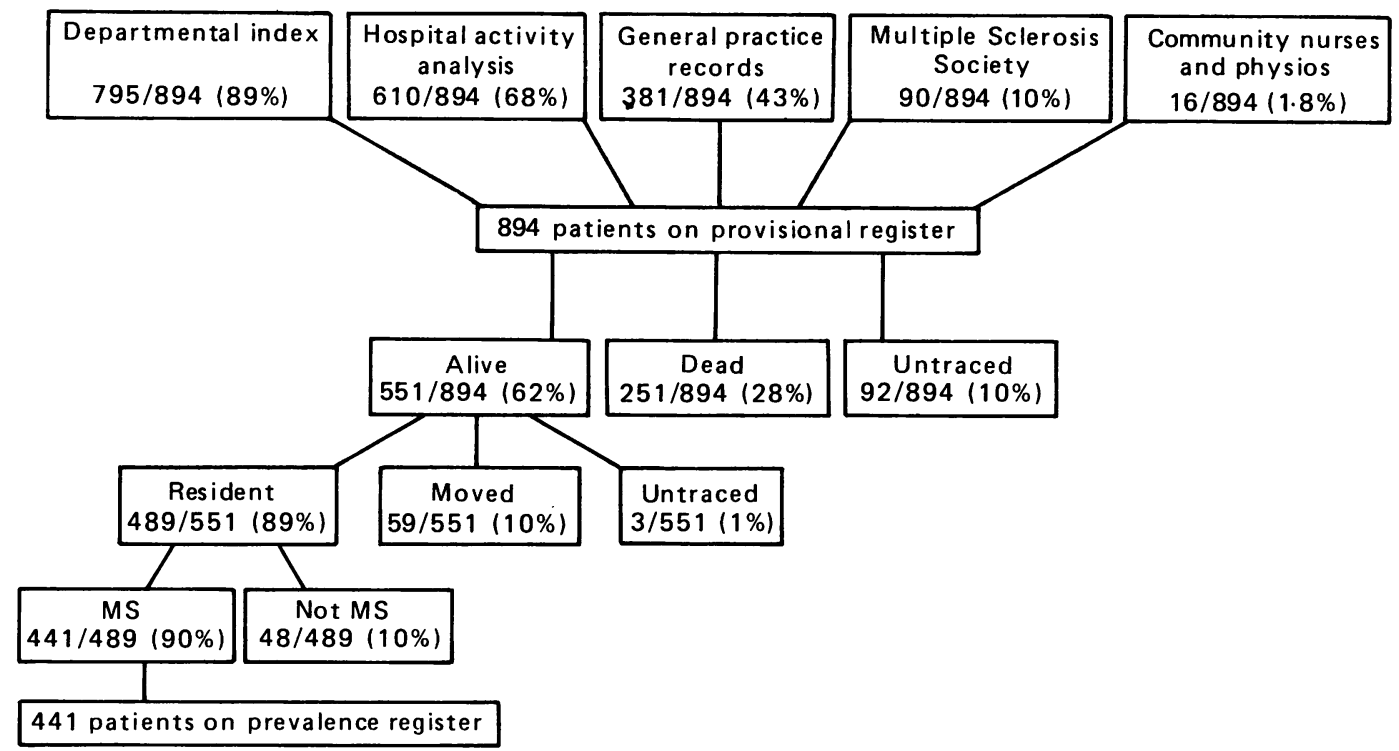

Fig Source and status of 894 patients on a provisional register of patients with multiple sclerosis in South Glamorgan on 1 January 1985. 
Table 2 Prevalence of multiple sclerosis in South Glamorgan by diagnostic category

\begin{tabular}{|c|c|c|c|c|}
\hline Category & Number & $(\%)$ & $\begin{array}{l}\text { Prevalence } \\
\left(/ 10^{5}\right)\end{array}$ & $\begin{array}{l}95 \% \\
\text { confidence } \\
\text { intervals }\end{array}$ \\
\hline $\begin{array}{l}\text { Poser et al } l^{17}: * \\
\text { CDMS } \\
\text { LSDMS } \\
\text { CPMS } \\
\text { LSPMS } \\
\text { MS ? classification } \\
\text { Suspected } \\
\text { Total }\end{array}$ & $\begin{array}{r}298 \\
20 \\
41 \\
1 \\
21 \\
60 \\
441\end{array}$ & $\begin{array}{r}67 \cdot 6 \\
4.5 \\
9 \cdot 3 \\
0.2 \\
4.8 \\
13.6 \\
100.0\end{array}$ & $\begin{array}{r}79.0 \\
5.3 \\
10.9 \\
0.3 \\
5.6 \\
15.9 \\
117.0\end{array}$ & $\begin{array}{r}(71-89) \\
(3-8) \\
(8-15) \\
(0-1 \cdot 5) \\
(3-9) \\
(12-21) \\
(106-128)\end{array}$ \\
\hline $\begin{array}{l}\text { Allison and Millar }{ }^{18} \text { : } \\
\text { Probable } \\
\text { Possible } \\
\text { Total }\end{array}$ & $\begin{array}{l}316 \\
125 \\
441\end{array}$ & $\begin{array}{r}71.6 \\
28.4 \\
100 \cdot 0\end{array}$ & $\begin{array}{r}83.9 \\
33 \cdot 1 \\
117.0\end{array}$ & $\begin{array}{r}(76-95) \\
(28-40) \\
(106-128)\end{array}$ \\
\hline
\end{tabular}

*CDMS, clinically definite multiple sclerosis; LSDMS, laboratory supported definite multiple sclerosis; CPMS, clinically probable multiple sclerosis; LSPMS, laboratory supported probable multiple sclerosis; MS ? classification, definite or probable multiple sclerosis (unverified); Suspected MS, "possible" multiple sclerosis but not "definite" or "probable" according to the Poser criteria."

Multiple Sclerosis Society and none from the records of community nurses. The use of both departmental notes and hospital activity analysis returns would therefore have identified $436 / 441(98.9 \%)$ of the prevalent cases.

The information on the provisional register was sent to the National Health Service Central Register and the local Family Practitioner Committee so that patients could be traced (fig). By combining the returns from these sources it was established that 551/ $894(61.6 \%)$ of the patients provisionally listed were alive, 251/894 (28\%) were dead and 92/894 (10.3\%) could not be traced on prevalence day (1 January 1985)-usually because their date of birth was unknown. Of the living $489 / 551(88.8 \%)$ were resident in South Glamorgan, $59 / 551(10 \cdot 7 \%)$ were temporarily resident or had moved and the whereabouts of $3 / 551$ $(0.5 \%)$ remained unknown on prevalence day. Of those alive and usually resident $315 / 489(64 \cdot 4 \%)$ were interviewed, $6 / 489(1.2 \%)$ failed to reply to three requests and $54 / 489(11 \%)$ did not wish to be seen. An agreed appointment was not kept by $7 / 489(1.43 \%)$, a further $3 / 489(0.6 \%)$ had died and $6 / 489(1.2 \%)$ moved since prevalence day. $39 / 489(8 \%)$ were not contacted at the request of their general practitioner and $59 / 489(12 \%)$ for other reasons; in most of the latter, examination of the notes revealed that another diagnosis had been made. In summary, 315/489 $(64.5 \%)$ of those alive and resident were classified on the basis of personal interview and 174/489 (35.5\%) from hospital or general practice records. $441 / 489$ $(90 \cdot 1 \%)$ had definite, probable or suspected multiple sclerosis and the diagnosis was rejected, from one or other category, in $48 / 489$ ( $9.9 \%)$.

Table 2 gives the diagnostic classification for those patients who were alive and usually resident on prevalence day (1 January 1985). The prevalence of multiple sclerosis in South Glamorgan was 441/ $376,718\left(117 / 10^{5}\right)$ of whom $381\left(86 \%\right.$ or $\left.101 / 10^{5}\right)$ had definite or probable disease and $60\left(14 \%\right.$ or $\left.16 / 10^{5}\right)$ had suspected multiple sclerosis on 1 January 1985. The diagnosis was confirmed by personal examination in $301 / 441(68 \%)$ individuals. Using the criteria of Allison and Millar, the prevalence of "probable" multiple sclerosis would have been $83 / 10^{5}$, the remainder of the patients being classified as possible multiple sclerosis $\left(34 / 10^{5}\right)$. Table 3 summarises the age and sexspecific prevalence rates. The age range of patients was 10-85 years with a mean of $48 \cdot 7$ years (SD 14.8). The mean age was 48 years (SD 15.6) for women and 50 years (SD 12.6) for men. Table 4 shows the estimated age of onset of multiple sclerosis. The mean age of onset was 32.2 years (SD 10.7) and diagnosis occurred, on average, at the age of 36.4 years (SD 11.8). The mean duration of the disease from onset to prevalence day was 16.5 years and this can be doubled to give an estimate of mean duration from onset to death of 33 years. Table 5 shows the estimated incidence from 1947 to 1984 . The mean is $5 \cdot 41 / 10^{5} /$ year and there has been a significant rise from $3 \cdot 3 / 10^{5} /$ year $(1947-49)$ to $8 \cdot 9 / 10^{5} /$ year (1983-4) which may reflect improved methods of ascertainment. However, average

Table 3 Prevalence of multiple sclerosis per 100,000 by age and sex in South Glamorgan

\begin{tabular}{|c|c|c|c|c|c|c|}
\hline \multirow[b]{2}{*}{ Age group (years) } & \multicolumn{2}{|c|}{ Male } & \multicolumn{2}{|c|}{ Female } & \multicolumn{2}{|c|}{ Total } \\
\hline & No & Rate & No & Rate & No & Rate \\
\hline
\end{tabular}


Table 4 Age at onset of multiple sclerosis in prevalent patients in South Glamorgan

\begin{tabular}{|c|c|c|c|}
\hline & Male & Female & Total \\
\hline Age group (years) & No $(\%)$ & No $(\%)$ & No $(\%)$ \\
\hline $\begin{array}{l}0-14 \\
15-24 \\
25-34 \\
35-44 \\
45-54 \\
55-64 \\
65-74 \\
75> \\
\text { Not known } \\
\text { Total }\end{array}$ & $\begin{aligned} 0 & (0) \\
30 & (20 \cdot 6) \\
47 & (32 \cdot 2) \\
31 & (21 \cdot 2) \\
21 & (14 \cdot 4) \\
4 & (2 \cdot 7) \\
0 & (0) \\
0 & (0) \\
13 & (8 \cdot 9) \\
146 & (100)\end{aligned}$ & $\begin{aligned} 5 & (1 \cdot 7) \\
74 & (25 \cdot 1) \\
97 & (32 \cdot 9) \\
63 & (21 \cdot 3) \\
31 & (10 \cdot 5) \\
7 & (2 \cdot 4) \\
0 & (0) \\
0 & (0) \\
18 & (6 \cdot 1) \\
295 & (100)\end{aligned}$ & $\begin{aligned} 5 & (1 \cdot 1) \\
104 & (23 \cdot 6) \\
144 & (32 \cdot 7) \\
94 & (21 \cdot 3) \\
52 & (11 \cdot 8) \\
11 & (2 \cdot 5) \\
0 & (0) \\
0 & (0) \\
31 & (7 \cdot 0) \\
441 & (100)\end{aligned}$ \\
\hline
\end{tabular}

incidence rates were consistently lower than those in Aberdeen for the period 1959-79. ${ }^{22}$ Table 6 compares the results from this survey with three recent studies carried out in the United Kingdom. The standardised prevalence ratio is similar to the recent figure obtained from Sutton, Surrey but significantly lower than the original and updated estimates from Aberdeen, north east Scotland.

\section{Discussion}

The epidemiological method can provide important clues to the remote causes of multiple sclerosis and other diseases by demonstrating temporal and geographical trends in distribution. In order to determine the pattern of the disease it is necessary to make reliable comparisons between studies carried out in different places and at different times. Difficulties arise in delineating the optimum size for study: under-ascertainment and error in diagnosis will contaminate studies based on very large populations, whereas confidence limits for prevalence estimates will widen if too small a denominator is used. In our study there were considerable variations in prevalence within the communities of South Glamorgan and for surveys of a disease like multiple sclerosis it is likely that a popula-
Table 5 Estimated incidence of multiple sclerosis in South Glamorgan from 1947 to 1984

\begin{tabular}{lcll}
\hline Year & Number & Population & $\begin{array}{l}\text { Incidence } \\
\left(/ 10^{5} / \text { year }\right)\end{array}$ \\
\hline $1947-49$ & 23 & 351294 & $3 \cdot 3$ \\
$1950-52$ & 66 & 351294 & $6 \cdot 3$ \\
$1953-55$ & 51 & 351294 & $4 \cdot 8$ \\
$1956-58$ & 66 & 380267 & $5 \cdot 8$ \\
$1959-61$ & 85 & 380267 & $7 \cdot 5$ \\
$1962-64$ & 57 & 380267 & $5 \cdot 0$ \\
$1965-67$ & 62 & 390269 & $5 \cdot 3$ \\
$1968-70$ & 53 & 390269 & $4 \cdot 5$ \\
$1971-73$ & 46 & 390269 & $3 \cdot 9$ \\
$1974-76$ & 65 & 390269 & $5 \cdot 6$ \\
$1977-79$ & 62 & 384042 & $5 \cdot 4$ \\
$1980-82$ & 78 & 384042 & $6 \cdot 8$ \\
$1983-84$ & 68 & 384042 & $8 \cdot 9$ \\
$1947-84$ & 782 & 390269 & $5 \cdot 4$ \\
\hline
\end{tabular}

tion of approximately half a million will be needed to provide adequate precision whilst remaining manageable within the resources of the team of investigators.

We have previously cited evidence from a variety of sources indicating that the frequency of multiple sclerosis is higher in Scotland than other parts of the United Kingdom. ${ }^{4}$ However, Williams and McKeron ${ }^{5}$ have argued that it is wrong to assume that all studies relating to the United Kingdom are comparable. Ascertainment has tended to be more complete in Scotland because the surveys are more recent; the study populations are small and estimates have been repeated, suggesting that legitimate comparisons should only be made between first surveys from different regions. First estimates from Sutton, (115/ $\left.10^{5}\right),{ }^{5}$ Southampton $\left(\mathrm{c} 110 / 10^{5}\right)^{23}$ and South Glamorgan $\left(117 / 10^{5}\right)$ in the southern United Kingdom give similar estimates of prevalence to earlier studies from Aberdeen, $\left(127 / 10^{5} \text { in } 1970\right)^{10}$ and Orkney $\left(108 / 10^{5}\right.$ in $1954)^{6}$ in the north of Scotland. However, agesex standardised prevalence ratios from South Glamorgan and Sutton are significantly lower than the

Table 6 Comparison of surveys from South Glamorgan, Sutton ${ }^{5}$ and Aberdeen ${ }^{102}$

\begin{tabular}{|c|c|c|c|c|}
\hline & S Glamorgan (1985) & Sutton (1985) & Aberdeen (1970) & Aberdeen (1980) \\
\hline $\begin{array}{l}\text { Population } \\
\text { Number } \\
\text { Prevalence } \\
\text { Probable } \\
\text { Early probable } \\
\text { Possible } \\
\text { Age } \\
\text { Duration } \\
\text { Age onset } \\
\text { Incidence } \\
\text { Female } \\
\text { SPR† }\end{array}$ & $\begin{array}{l}376718 \\
441 \\
117(106-128) \\
316(72 \%) \\
* \\
125(28 \%) \\
49 \\
16 \cdot 5 \\
32 \\
5 \cdot 41(1947-84) \\
67 \% \\
139(126-150)\end{array}$ & $\begin{array}{c}169600 \\
195 \\
115(99-131) \\
147(75 \%) \\
29(15 \%) \\
19(10 \%) \\
49 \\
15 \cdot 4 \\
34 \cdot 1 \\
5(1974-84) \\
69 \% \\
129(111-147)\end{array}$ & $\begin{array}{c}440176 \\
557 \\
127(117-138) \\
310(56 \%) \\
154(28 \%) \\
93(16 \%) \\
48 \cdot 2 \\
14 \cdot 4 \\
34 \cdot 2 \\
5 \cdot 3(1959-73) \\
62 \% \\
153(140-166)\end{array}$ & $\begin{array}{l}471000 \\
839 \\
178(165-190) \\
682(80 \cdot 3 \%) \\
157(18 \cdot 7 \%) \\
45 \cdot 1 \\
14 \cdot 8 \\
34 \cdot 5 \\
7 \cdot 2(1977-80) \\
65 \% \\
221(184-261)\end{array}$ \\
\hline
\end{tabular}

* Probable and early probable categories amalgamated.

+SPR, standardised prevalence ratio using Northern Ireland $1961=100$ 
earlier estimate from Aberdeen. The overall estimate of prevalence has risen since this investigation was performed due to the expansion of neurological services and availability of hospital morbidity registers, computerised discharge returns and laboratory tests supplementing the criteria for diagnosis in clinical practice and epidemiological studies..$^{22}$ It is likely that the methodologies used in recent surveys from the southern United Kingdom have been superior to those originally used in the north and the degree of underascertainment is probably much lower. Support for this hypothesis comes from the observation that prospectively observed incidence rates in South Glamorgan are now in equilibrium with the mortality rates in prevalent patients (unpublished observations); the implication is that prevalence is unlikely to rise substantially as serial studies are performed, unless there is a steady increase in disease duration.

We would therefore suggest that it is appropriate to compare the first prevalence estimates in the south with the more recent and significantly higher estimates from Aberdeen ${ }^{22}$ and Orkney ${ }^{24}$ because the degree of ascertainment in these studies is probably similar. Such analysis reveals a significant north-south gradient which may have a genetic basis. Sutherland ${ }^{6}$ suggested that Nordic populations are more susceptible than Celtic populations within Scotland, and Shepherd ${ }^{10}$ observed that the frequency of multiple sclerosis in Europe correlates with the distribution of class 1 HLA antigens. We have also suggested that the gradient in the United Kingdom is influenced by the frequency of the closely linked class 2 allele HLADR2. ${ }^{41}$ There are still comparatively few areas where combined prevalence and immunogenetic studies have been performed but the greater availability of hospital and general practice morbidity registers should allow the number of comparable surveys to increase in the future; it will then be possible more fully to exploit the epidemiological method in understanding the aetiology of multiple sclerosis.

\section{References}

1 Allison RS. Disseminated Sclerosis in North Wales. Brain 1931;53:391-430.

2 Limburg CC. The geographic distribution of multiple sclerosis and its estimated prevalence in the United States. Multiple sclerosis and the demyelinating diseases. Proceedings of the Association for Research into Nervous and Mental Disease 1950;28:15-24. Baltimore: Williams and Wilkins.

3 Kurtzke JF. A reassessment of the distribution of multiple sclerosis. Parts 1 and 2. Acta Neurol Scand 1975;51:110-57.

4 Swingler RJ, Compston DAS. The distribution of multiple sclerosis in the United Kingdom. $J$ Neurol Neurosurg Psychiatry 1986;49:1115-24.

5 Williams ES, McKeron RO. Prevalence of multiple sclerosis in a south London borough. Br Med J 1986; 293:237-9.
6 Sutherland JM. Observations on the prevalence of multiple sclerosis in Northern Scotland. Brain 1956;79: 635-54.

7 Stocks P. Multiple sclerosis distribution in England and Wales and parts of Europe. J Hyg (Camb.) 1971;69(3): 373-89.

8 Stewart GJ, Kirk RL. The genetics of multiple sclerosis. In: Hallpike J, Adams C, Tourtellote W, eds. Multiple sclerosis. London: Chapman and Hall, 1982:197-228.

9 Roberts DF, Roberts MJ, Poskanser DC. Genetic analysis of multiple sclerosis in Orkney. $J$ Epidemiol Community Health 1979;33:229-35.

10 Shepherd DI, Downie AW. Prevalence of multiple sclerosis in North-East Scotland. Br Med J 1978;2: 314-6.

11 Swingler RJ, Kirk PF, Darke C, Compston DAS. HLA and multiple sclerosis in South-East Wales. J Neurol Neurosurg Psychiatry 1987;50:1153-5.

12 Office of Population Censuses and Surveys. Census 1981. County Report South Glamorgan parts 1 and 2. London: HMSO, 1982.

13 Watkins IM. ABO blood group distribution in Wales in relation to human settlement. In: Harper PS, Sunderland E, eds. Genetic and Population Studies in Wales. Cardiff: University of Wales Press, 1986: 118-46.

14 Carter H. Population movements into Wales: an historical review: In: Harper PS, Sunderland E, eds. Genetic and Population Studies in Wales. Cardiff: University of Wales Press, 1986:31-51.

15 Welsh Office. Hospital Activity Analysis statistics for 1981. Cardiff: Welsh Office, 1982.

16 Office of Population Censuses and Surveys. The National Health Service Central Register as an aid to Medical Research. A Guide for Potential Applicants. London: OPCS, 1982.

17 Poser CM, et al. New diagnostic criteria for multiple sclerosis: guidelines for research protocols. Ann Neurol 1983;13:227-31.

18 Allison RS, Millar JHD. Prevalence and Familial Incidence of Disseminated Sclerosis (A Report to the Northern Ireland Hospitals Authority on the results of a Three-Year Survey). Prevalence of Disseminated Sclerosis in Northern Ireland. Ulster Med J 1954;23 (suppl No 2):5-27.

19 Poskanser DC, Schapira K, Miller H. Epidemiology of multiple sclerosis in the counties of Northumberland and Durham. J Neurol Neurosurg Psychiatry 1963;26: 368-76.

20 Millar JHD. Multiple sclerosis in Northern Ireland. In: Clifford Rose F, ed. Clinical Neuroepidemiology. Tunbridge Wells: Pitman Medical, 1980:222-7.

21 Lentner C. Geigy Scientific Tables. Basle: Ciba Geigy, 1982:223-4.

22 Phadke JG, Downie AW. Epidemiology of multiple sclerosis in the north east (Grampian Region) of Scotland-an update. J Epidemiol Community Health 1987;41:5-13.

23 Mclellan DL, Roberts MHD. Prevalence of multiple sclerosis in a south London borough (letter). Br Med J 1986;293:507.

24 Cook SD, Cromarty MB, Tapp W, Poskanser D, Walker JD, Dowling PC. Declining Incidence of Multiple Sclerosis in the Orkney Islands. Neurology 1985;35: 545-51. 